\title{
A new Approach towards Cost and Benefit Enterprise Architecture Analysis
}

\author{
Ali Abediniyan \\ Department of Computer, \\ Science and Research Branch, \\ Islamic Azad University, \\ Khouzestan, Iran
}

\author{
Mehran Mohsenzadeh \\ Department of Computer, \\ Science and Research Branch, \\ Islamic Azad University, \\ Tehran, Iran
}

\author{
Mashalla Abbasi Dezfouli \\ Department of Computer, \\ Science and Research Branch, \\ Islamic Azad University, \\ Khouzestan, Iran
}

\begin{abstract}
Organizations managers need to develop comprehensive information technology programs with an Enterprise Architecture (EA) strategy, in order to decrease the costs and different risks, and also increase efficiency, utility and effectiveness of the organization. Due to expensive implementation of enterprise-wide scenarios, a continuous evaluation can measure different strategies in terms of different aspects, and according to the current conditions of the organization and select the most suitable strategy. Therefore organizations can analyze different strategies and decision options in terms of cost and benefit in order to make suitable decisions according to the utilities of the organization. In this paper, a new method has been used to analyze the Enterprise Architecture scenarios in terms of cost and benefit. The suggested method is presented by a step by step process in which CBAM method has been utilized to measure the cost. This approach ranks enterprise scenarios, using knowledge and experiences of the enterprise experts. The applicability of the proposed approach is demonstrated using a practical case study.
\end{abstract}

Keywords: Enterprise Architecture Analysis, Return of Investment (ROI), quality attributes, cost and benefit, organizational capitals.

\section{INTRODUCTION}

Enterprises are complex, highly integrated systems comprised of processes, organizations, information and supporting technologies, with multifaceted interdependencies and interrelationships across their boundaries [4]. Conduct and control of organization changes need to have exact information from the current conditions, a good view toward the desirable conditions and a clear program to move from the current conditions to a desirable and pleasant status [1].

Organizations managers need to develop comprehensive information technology programs with an Enterprise Architecture (EA) strategy, in order to decrease the costs and different risks, and also increase efficiency, utility and effectiveness of the organization [1]. Enterprise Systems Architecting is a new strategic approach which takes a systems perspective, viewing the entire enterprise as a holistic system encompassing multiple views such as strategic view, policy/external environment view, organization view, process view, knowledge view, information technology view, product view, service view and relations among these views, in an integrated framework [4][5]. Enterprise architecture provides necessary information platform and strategies to analyze organizations' current conditions, recognize desirable targets by analyzing, examining and selecting from the different variables, and also move from the current status to the desired status. Decisions are made about the alternatives in the context of the business model, technology strategy, culture, purpose, and other factors [4]. By including all such data the architecture can provide the capability to make informed investment decisions, decisions based on a complete understanding of the complex interrelationships that exist among the people, processes, and technology solutions that make up the enterprise. [4]. EA analysis is the application of property assessment criteria on EA models [2].

Due to expensive implementation of enterprise-wide scenarios, examining advantages and disadvantages of the suggested programs before execution would be valuable. In this case, waste of enterprise resources will be significantly prohibited, and the analysis and examination of different approaches can determine not only the selection of the best approach among others, but also the weakness and strengths of the current condition of the organization, in order to determine the guidelines of organization development in future [3].

One of the Software Architecture analysis methods is CBAM. CBAM makes a bridge between development of software and organization economy during the architecture process [17]. One of the main advantages of this method is to provide a measurement scale to return investments and help prepare an evaluated program for architecture development and investment [18]. In the suggested method, CBAM idea was used to measure the benefit of organizational decisions.

Different methods have been already presented to analyze enterprise architecture but none has directly assessed organizational decisions in terms of cost and profit. The main purpose of this paper is to suggest a method to analyze cost and profit of enterprise architecture based on quality attributes. In the suggested method options of enterprise architecture are be profitable and then their costs will be estimated. Therefore investment return of each plan will be obtained. By measurement of investment return of scenarios, waste of financial, human and organizational capitals can be prevented. Also, the enterprise options can be explained economically to execute the decisions with the minimum risk. Presence of a method to analyze cost and benefit of EA can help the organizations select the optimum EA scenarios according to organizations' utilities. In the suggested method, the organization utilities include quality attributes.

It is noteworthy, in during this paper, cases is compared that these can be decisions, scenarios, projects, or goals.

This paper is structured in the following way. Section 2 introduces the current methods in the field of Enterprise Architecture Analysis. In section 3 the proposed method is presented to analyze the cost and benefit of EA scenarios. In section 4 , a case study has been applied to demonstrate the application of the suggested method and provide an environment to measure its executive credit and the results show the internal validity of the method. Finally, the paper concludes and future work are discussed in section 5. 


\section{RELATED WORK}

Different methods have been presented to analyze Enterprise Architecture (EA). Some of the methods are based on a special framework and some are independent from framework and are provided based on EA concepts. Some of the methods concentrate on analysis and measurement of EA projects in terms of techniques.

The related work is discussed in this paper are from three perspectives:

1. It is clear from the study of the Enterprise Architecture analysis methods that the most provided methods analyze data according to EA models and consider quality attributes. Only the approaches provided by Neimann [6], Khayyami [3] and Razavi [2] use both EA information and EA models.

2. from the studies methods, the one presented by $\mathrm{Yu}$ and associates [7], incompletely and in elementary forms, the one introduced by Jacob and Jonkers [8], the one presented by KHayyami [3], the one provided by Razavi [2] and also the ones presented by researcher group of KTH university of sweden [9][10][11][12][13][14][15], directly analyze quality and quantity properties of the methods and other methods analyze non applicable properties or enterprise efficiencies.

3. In Neimann [6], cost and benefit of enterprise efficiency are studied abstract. Frank and associates [16], is also a method to project and apply business indicator system in which most attributes are economical and indicators data are provided based on statistical data obtained from the enterprise behavior.

These methods mostly study the EA models formally and determine the analysis parameters, but no method has been provided to analyze the cost and benefit of organization decisions directly. The proposed method has been analyzed based on quality attributes' benefits and decisions cost. Due to expensive implementation of enterprise-wide scenarios, their evaluations is very important in terms of cost and benefit, and the organization can estimate cost and benefit of their decisions and find a way for accurate and informed decisions.

\section{THE PROPOSED METHOD}

The suggested process is shown in figure 1, As it can be seen in the figure, the process includes six main steps. In this process, in step 5 divide difference interpolation method has been used to obtain quality attributes utility. In steps 2,3 and 4 information are collected according to the knowledge and experience of enterprise experts. Also, total cost is estimated by managers and advisors for each project of the organization. It should be noted that there are different formal methods of estimating costs according to the activities and the

\begin{tabular}{|l|l|}
\hline $\begin{array}{l}\text { Step 1 } \\
\text { Step 1-1 }\end{array}$ & $\begin{array}{l}\text { Determination of scenario organization } \\
\text { Determination of scenarios activities }\end{array}$ \\
\hline Step2 & Determination of quality attributes \\
\hline Step 3 & Determination of the levels of activities response \\
\hline Step 4 & Assignment of activities benefits \\
\hline Step 5 & $\begin{array}{l}\text { Computation of the quality attributes utility and } \\
\text { estimation of total cost }\end{array}$ \\
\hline Step 6 & Analysis and ranking based on ROI \\
\hline
\end{tabular}

Figure 1. The proposed process towards Enterprise

$$
\text { Architecture }
$$

$\underline{\text { www.ijcat.com }}$ organization can use any of the current methods in this step. In step 6 , organizational scenarios prioritized according to ROI.

\subsection{The proposed method steps}

Step1: Determination of scenarios of the organization

Enterprise goals may include adding/changing new business processes, changing enterprise structure, changing enterprise departments, variation of business market, changing economic policies and ....

In this step, managers and consultants of the organization, determine scenarios of the organization. These scenarios can have any level of granularity or be related to any time section. For example, annual projects of an organization. Sometimes, organizations need to perform projects to make changes regarding their needs.

Step1-1: Determination of scenarios activities.

Organizations need to do some activities in order to reach and execute EA scenarios, and they are specified in this step. These activities contain sub activities and these need executable programs to be performable.

Step2: determination of attributes

In each organization, there are some specified attributes and indicators for measuring efficiency of organization decisions. The indices of organization purpose measurement can be determined by Delphi technique. Delphi technique is a method which gathers opinions of experts by distribution of a questionnaire and then reaches them to the opinion of the majority.

In the proposed method a questionnaire is distributed between experts of different regions and their opinions are collected. Therefore, the most important quality attributes will be determined. It should be noted that indices and attributes are named as quality attributes here.

\section{Step3: Determination of the levels of activities response}

In this step best, worst, current and desired responses of the quality attributes are extracted for each of the goal activities. Quality attributes response levels are weighted by each of the experts. These values are assigned in percent.

The four independent values are described as below:

The best status: In this status the best status of the goal is expressed from the view point of stakeholders and of course there is no need to improve more than this value.

The worst status (minimum needs): This status specifies the minimum expectations. It should be 
considered that the best and the worst status are assumed as the reference points and, current and desired status are measured on their basis.

Current status: A ratio of the best and the worst$\mathrm{X} \%$

Desired status: A ratio of the best and the worstY\%

Regarding the fact that attributes and utilities are for the decisions and goals of the whole organization, a scenario or goal could not have a zero value for an attribute in all statuses.

Step4: assignment of activities benefits

In this step a utility is assigned to each level of quality attributes response (Best, Worst, Current and Desired status), related to it. This value assignment is done by the enterprise experts.

utility: The profit obtained for the stakeholders of the organization is called utility. The value of utility is from 100

Step 5: Computation of the quality attributes utility and estimation of total cost

In this step, the desired utility of quality attributes is obtained by Formula. 1 and $F(x)$ is obtained by divide difference interpolation method. In interpolation, $\mathrm{Xi}$ is the levels of activities response (output of step 3 ) and, $\mathrm{Yi}$ is the utility of activities or duties (output of step 4). After obtaining function $F(x)$, level of response of the quality attribute in the project are given values and the desired utility will be obtained. Then the quality attribute utility is obtained by formula. 2 .
$\mathrm{F}(\mathrm{X}=$ reply of quality attribute by scenario $)=$ Desired utility (1)

The quality attribute utility= desired utility - current utility

Utility of the project is the sum of utility from each activity. Also, in this step the total cost is estimated by the organization.

\section{Step6: Analysis and ranking based on ROI}

In previous steps, the total benefit of the project was measured for each of the purposes or the organization projects towards the quality attributes. The project cost is also estimated. Therefore, ROI can be measured for each scenario in EA regarding formula.3.

$R O I_{i}=\frac{B_{i}}{C_{i}}$

\section{A CASE STUDY USING THE METHOD}

In this section it's been tried to check the validity of the suggested method by choosing an appropriate project for a case study. Our case study is conducted in Ports \& Maritime Organization of Iran (PMO). This enterprise as the maritime administration of Iran administers the ports and commercial maritime affairs of the country. Till some time ago, this enterprise was working according to the responsibilities defined by the Ministry of Road and Transport, but now some changes has occurred to the responsibilities and the organizational structure, and a new version of organizational chart and functionality description will be announced. So business process and functionality maintenance seems to be an important issue to be considered in an EA solution proposed for PMO. 
In the following, steps of the suggested method will be described with the so-called case study.

\section{Step1: Determination of scenarios of the organization}

The following scenarios are parts of immense goals of the organization in 2011.

1- Increasing the capacity of passenger transportation

2- Improvement of the security level

\section{Step1-1: Determination of scenarios activities}

In this stage, activities and duties considered to reach the immense goals are determined.

1-Increasing capacity of passenger transportation

1-1-Completion and development of passenger wharves

2-Improvement of security level

2-1- preferment of security level of maritime in navy

2-2-Improvement of security level of sailor degrees

2-3-Establishment and execution of Information Security Management System(ISMS)

2-4-Design and development of Information Technology

2-5-Estimation of damages, design and performance of protective systems

Step2: Determination of attributes

As mentioned above, indicators are the quality attributes of an organization, and are as follow:
1- Flexibility
2- Efficiency or on time services
3- Security
4- Interaction and extensibility levels
5- Usability or satisfaction of the customers
6- Investment absorption

Step3: Determination of the levels of activities response In this step and the next one, four expert viewpoints were used regarding the goals and activities of the organization. Table 1 shows response levels of the attributes by one of the experts which is related to the first goal. Also, table 2 shows results of the second goal by three other experts of the organization.

\section{Step4: assign of activities or duties benefit}

In this step, a utility was assigned to each response level of the quality attributes (the best, worst, current and desired status), relating to that status. Information about this stage is shown in tables 3 and 4.

Step5: Computation of the quality attributes utility and estimation of total cost

Table 2. Quality attributes response levels associated by expert \#2, \#3, \#4

Table l. Quality attributes response levels associated by expert \#1

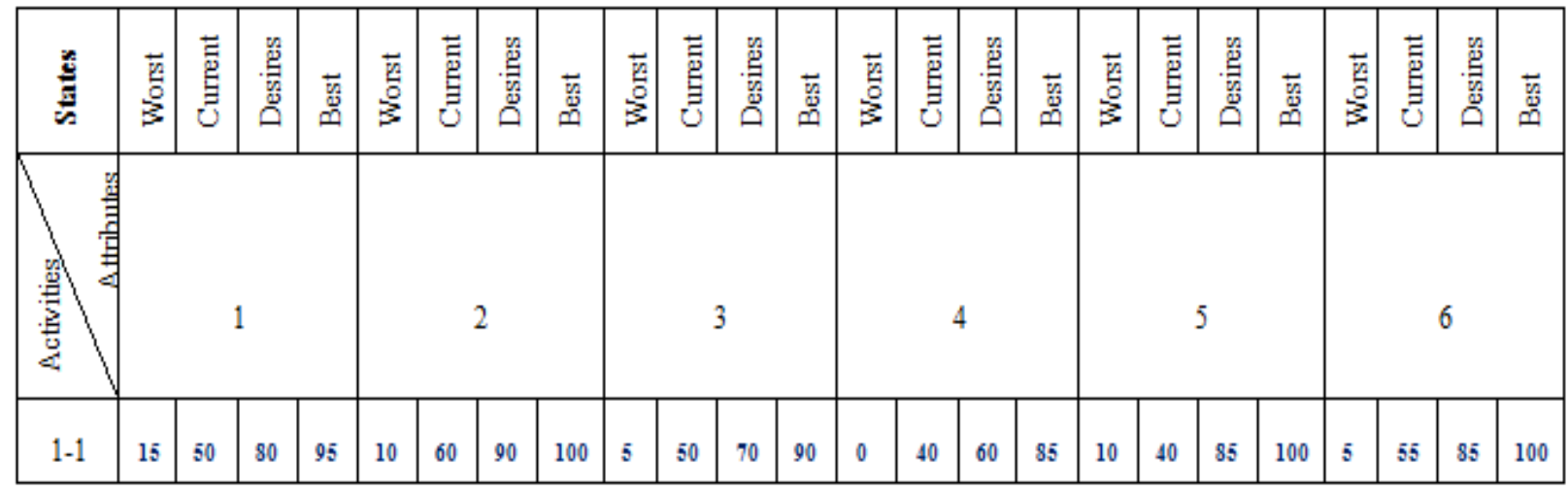

\begin{tabular}{|l|l|l|l|l|l|l|l|l|l|l|l|l|l|l|l|l|l|l|l|l|l|l|l|l|l|}
\hline & -4 & 0 & 0 & 0 & 0 & 0 & 0 & 0 & 0 & 10 & 61. & 90 & 100 & 8. & 48 & 81. & 91 & 0 & 0 & 0 & 0 & 0 & 0 & 0 & 0 \\
\hline $2-5$ & 0 & 0 & 0 & 0 & 0 & 0 & 0 & 0 & 5 & 45 & 90 & 100 & 0 & 0 & 0 & 0 & 0 & 0 & 0 & 0 & 0 & 0 & 0 & 0 \\
\hline
\end{tabular}


In this step, by using Newton divided difference interpolation method, utility of each quality attribute was measured for each goal and their results are shown in tables 5 and 6 .

\begin{tabular}{|l|c|c|c|}
\hline Attributes & $\begin{array}{c}\text { response by } \\
\text { scenario }\end{array}$ & \\
\hline
\end{tabular}

Table 3. Utility associated activities by expert \#1

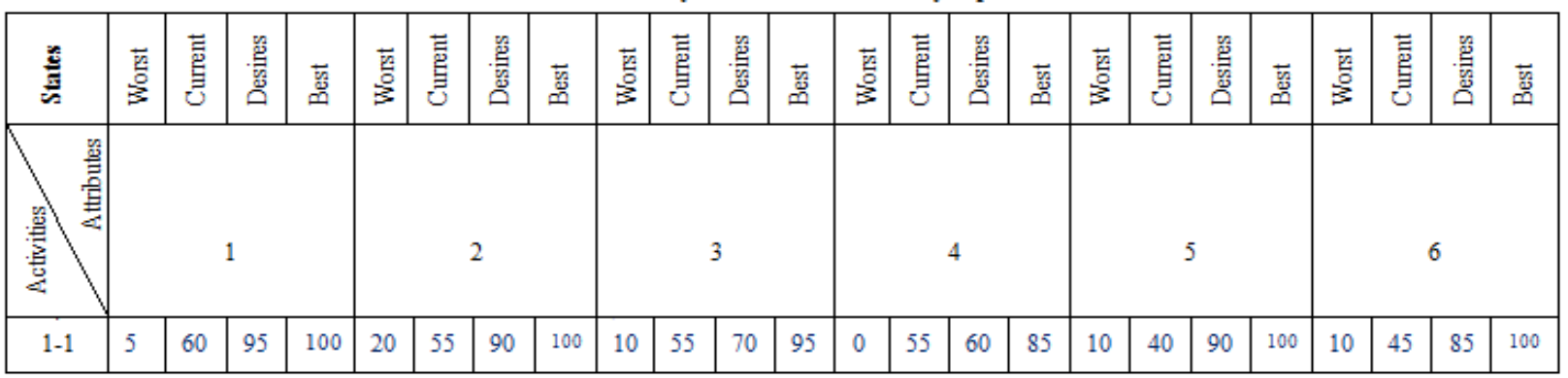

Table 4 . Utility associated activities by experts \#2, \#3, \#4

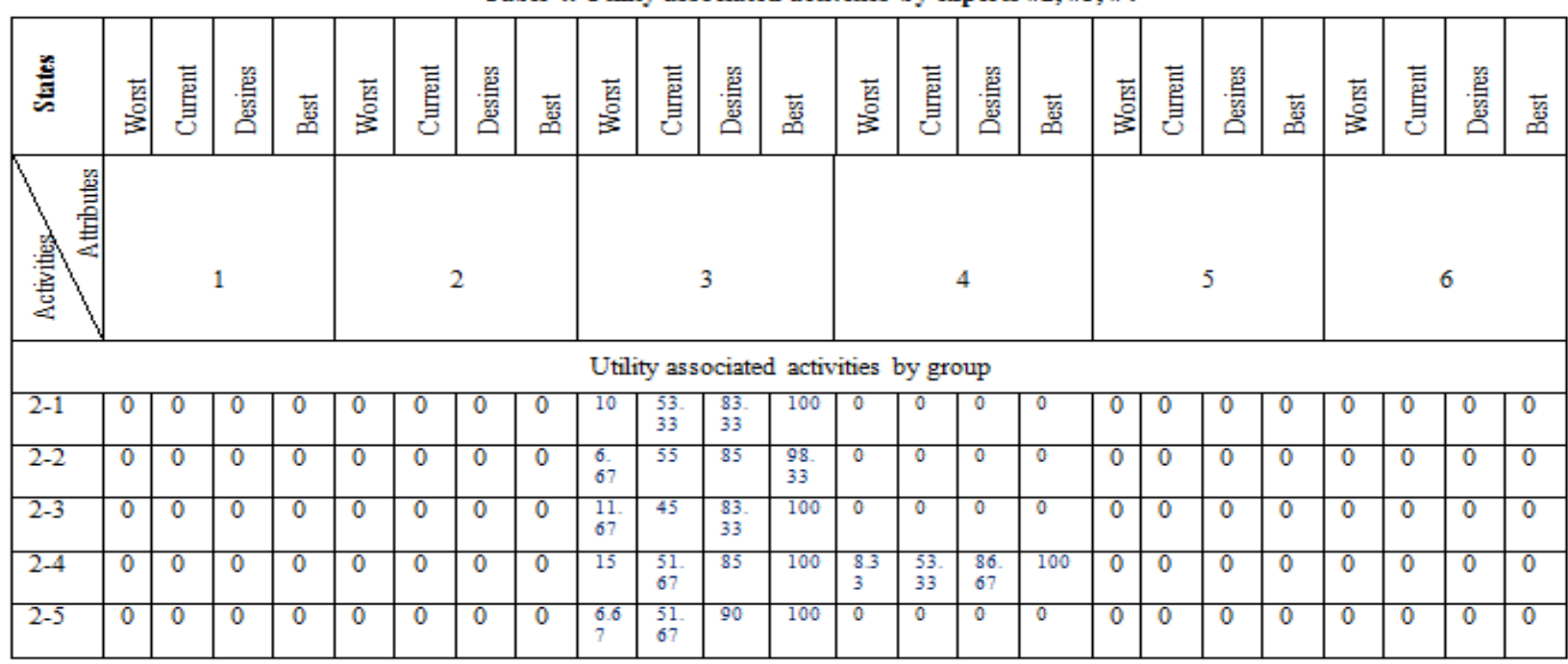

\section{Step6: Analysis and ranking based on ROI}

For each one of the purposes or projects of the organization the level of its benefit has been calculated against the quality attributes and the project cost was also estimated.

Therefore, for each scenario of EA the ROI can be calculated. Formulas 4 and 5 obtain the ROI for each project.

$$
R O I_{1}=\frac{175.1253}{150}=1.1675
$$

(4)

$$
\mathrm{ROI}_{2}=\frac{167.8127}{130}=1.2909
$$

So, ranking of scenarios are shown in table 7. As it was mentioned scenario 2 is more prioritized than scenario 1 in terms of ROI. In addition the organization can explain its projects economically and then codify a program to execute it.

Table 5. Utility associated for scenario 1

\begin{tabular}{|c|c|c|c|}
\hline Scenario & Quality & $\begin{array}{c}\text { Quality } \\
\text { attribute }\end{array}$ & Utility \\
\hline
\end{tabular}

\begin{tabular}{|c|c|c|c|}
\hline \multirow{2}{*}{} & 1 & $0 / 7$ & 24.5788 \\
\cline { 2 - 4 } & 2 & $0 / 8$ & 18.5565 \\
\cline { 2 - 4 } & 3 & $0 / 8$ & 25.6731 \\
\cline { 2 - 4 } & 4 & $0 / 8$ & 21.6667 \\
\cline { 2 - 4 } & 5 & $0 / 95$ & 57.3086 \\
\cline { 2 - 4 } & 6 & $0 / 75$ & 27.3416 \\
\hline
\end{tabular}

Table 6. Utility associated for scenario 2

\begin{tabular}{|c|c|c|c|}
\hline Scenario & $\begin{array}{c}\text { Quality } \\
\text { Attributes }\end{array}$ & $\begin{array}{c}\text { Quality } \\
\text { attribute } \\
\text { response by } \\
\text { scenario }\end{array}$ & Utility \\
\hline \multirow{2}{*}{} & 3 & $0 / 85$ & 32.9106 \\
\cline { 2 - 4 } & 3 & $0 / 7$ & 15.6008 \\
\hline
\end{tabular}




\begin{tabular}{|c|c|c|c|}
\hline \multirow{3}{*}{2} & 3 & $0 / 85$ & 52.4593 \\
\cline { 2 - 4 } & 4 & $0 / 7$ & 33.3978 \\
\cline { 2 - 4 } & 3 & $0 / 75$ & 14.1398 \\
\cline { 2 - 4 } & 3 & $0 / 8$ & 29.3044 \\
\hline
\end{tabular}

\section{CONCLUSION AND FUTURE WORK}

In this paper, we present a cost and benefit method to evaluate scenarios of EA. The proposed method helps managers and decision makers select EA decisions regarding cost and benefit ranking and the best scenario of EA in terms of ROI. Also, organization can explain its projects economically and then codify a program to execute it.

As future work, indices can be divided into two positive and negative (benefit and cost) groups and weighted. To do this, group decision making methods like AHP and TOPSIS can be introduced to evaluate EA scenarios.

\section{REFERENCES}

[1] Samadi Avansar, A., "An Introduction to The Enterprise Architecture (For Managers)", 2006.

[2] Razavi, M., "A New Framework for EA Quality Attribute Analysis", thesis, Science and Research Branch, Islamic Azad University, Tehran, Iran, 2011.

[3] KHayami, R., "Enterprise Architecture Analysis and Evaluation", thesis, Department of Engineering, Shiraz University, Iran, 2009.

[4] Nightingale, D.J., Rhodes, D.H., "Enterprise Systems Architecting: Emerging Art and Science within Engineering Systems", MIT Engineering Systems Symposium, pp. 29-31, 2004.

[5] Rhodes, D.H., Ross, A.M., Nightingale, D.J., "Architecting the System of Systems Enterprise: Enabling Constructs and Methods from the Field of Engineering Systems", 3rd Annual IEEE Systems Conference, Vancouver, BC, pp. 190-195, 2009.

[6] Niemann, K.D., "From Enterprise Architecture to IT Governance ElementsofEffective IT Management, Vieweg+Teubner, Wiesbaden, Germany, 2006.

[7] Yu, E., Strohmaier, M., Deng, X., "Exploring intentional modeling and analysis for enterprise architecture", Proceedings of the EDOC 2006 Conference Workshop on Trends in Enterprise Architecture Research (TEAR 2006), Hong Kong, IEEE Computer Society Press, pp. 32, 2006.

[8] Jacob, M.E, Jonkers, H., "Quantitative analysis of enterprise architectures", In Konstantas, D., Bourrieres, J.P., Leonard, M., Boudjlida, N., eds.: Interoperability of Enterprise Software and Applications, Geneva, Switzerland, Springer, pp. 239-252, 2006.

[9] Johnson, P., Johansson, E., Sommestad, T., Ullberg, J., "A Tool for Enterprisen Architecture Analysis", in Proceedings of the 11th IEEE Enterprise Distributed
Object Computing Conference, IEEE Computer Society, USA, pp. 142-156, 2007.

[10] Johnson, P., Lagerström, R., Närman, P., Simonsson M., "Enterprise architecture analysis with extended influence diagrams", Information Systems Frontiers. 9(2-3), pp. 163-180, 2007.

[11] Johnson, P., Lagerström, R., Närman, P., Simonsson, M., "Extended Influencen Diagrams for System Quality Analysis", Journal Of Software (JSW), 2(3), pp. 30-42, 2007.

[12] Johnson, P., Lagerström, R., Närman, P., Simonsson, M., "Extended Influence Diagrams for Enterprise Architecture Analysis", in Proceedings of the 10th IEEE Enterprise Distributed Object Computing Conference, pp. 3-12, 2006.

[13] Johnson, P., Nordstrom, L., Lagerstrom, R., "Formalizing analysis of enterprise architecture", In: Doumeingts G, Muller J, Morel G et al (eds) Enterprise InteroperabilityNew Challenges and Approaches, Springer London, pp. $35-44,2006$.

[14] Lagerström, R., "Analyzing System Maintainability Using Enterprise Architecture Models" Proceedings of the 2nd Workshop on Trends in Enterprise Architecture Research (TEAR'07), St Gallen, Switzerland, pp. 31-39, 2007.

[15] Lagerström, R., Johnson, P., "Using Architectural Models to Predict the Maintainability of Enterprise Systems", 12th European Conference on Software Maintenance and Reengineering, pp. 248-252, 2008.

[16] Frank, U., Heise, D., Kattenstroth H., Schauer H., "Designing and utilizing business indicator systems within enterprise models-outline of a method", in Proceedings of Modeling Business Information Systems Conference (MobIS 2008), Saarbrucken, Germany, pp. 89-1, 2008.

[17] Clements, P., Kazman, R., Klein, M., "Evaluating Software Architecture: Methods and Case Studies",2nded Addison- Wesley, Reading, MA, USA, 2002.

[18] IEEE, "IEEE standard recommended practice for architecture description", IEEE Std 1471-2000, 2000. 